\title{
You Want to Know the Truth? Then Don't Mimic!
}

\section{The Link Between Mimicry and Lying}

\author{
Paweł Muniak , Dariusz Dolinski², Tomasz Grzyb², Katarzyna Cantarero, ${ }^{2,3}$, \\ and Wojciech Kulesza ${ }^{1}$ \\ ${ }^{1}$ Center for Research on Social Relations, Faculty of Psychology in Warsaw, SWPS University of Social Sciences and Humanities, \\ Warsaw, Poland \\ ${ }^{2}$ Social Behavior Research Center, Faculty of Psychology in Wrocław, SWPS University of Social Sciences and Humanities, \\ Wroctaw, Poland \\ ${ }^{3}$ University of Essex, Department of Psychology, Colchester Campus, Colchester, United Kingdom
}

\begin{abstract}
Clinical psychologists have frequently reported that similarity in movements can be greatly beneficial. It increases rapport and favors a better understanding of clients' emotions. Social psychologists have shown that mimicking instills greater trust in the mimicker and that mimickees disclose more intimate information. Therefore, mimicry seems to be an ideal tool to implement during therapeutic interventions. However, the current study reveals a potentially perilous outcome stemming from mimicry: mimicked (verbally - Study $1, N=49$; nonverbally - Study 2, $N=40$ ) participants were more eager to cheat the mimicker. This means that incorporating mimicry into the therapeutic process may lead to clients misinforming therapists. The discussion section describes some caveats associated with the experiments and suggests directions for future research.
\end{abstract}

Keywords: mimicry, lying, therapeutic process, honesty, synchrony attunement

\section{Benefits of Mimicry}

Unconscious mimicry is an essential element of all social interactions. Imitating verbal and nonverbal behaviors and emotions is beneficial for mimickers because it leads to an increased level of trust from the mimickee (Swaab et al., 2011). Other benefits include an increased willingness to receive help (Van Baaren et al., 2004) and an increased likelihood of being liked (Kulesza et al., 2015) and perceived as attractive (Guéguen, 2009). Moreover, people who are mimicked are more willing to answer personal questions (Guéguen et al., 2013). At the same time, mimickers are less accurate at detecting lies (Stel et al., 2009). Against the backdrop of this evidence, across two studies, we explore the possible disadvantage of mimicry: people who are mimicked may be more willing to share false information.

The interest in imitation directly stems from clinical psychology. One key claim was that postural congruence is crucial for emotional rapport between interacting people (Dabbs, 1969; LaFrance \& Broadbent, 1976), and a better holistic understanding between clinician and patient (Charny, 1966). More contemporary literature has repli- cated these findings, showing that mimicry increases the probability of therapeutic success (Paulick et al., 2018). In addition, higher nonverbal synchrony between therapist and client embodies a patient's self-reported quality of the therapeutic relationship (Ramseyer \& Tschacher, 2011).

A more general explanation for the benefits of mimicry may be found in the theory of mind, which is the potential to understand the emotions, intentions, and ideas of others (Premack \& Woodruff, 1978). It is widely postulated that this deep understanding happens through mimicry (Gallese et al., 2004; Meltzoff \& Gopnik, 1993; Stel et al., 2008).

\section{Costs of Mimicry}

Mimicry may not always be positive. Research has also shown that mimicry can lead to the mimickee committing negative or damaging behavior. For example, mimickees may comply with stereotypes about their race (black men are worse at math) or gender (women are worse at math) (Leander et al., 2011), and mimickees show impaired 
ability to assess the emotions expressed by the mimicker (Kulesza et al., 2015). Research has also uncovered costs for the mimicker: In one study, participants were either deceived or told the truth during an interaction with another individual. During the interaction, participants were asked to mimic (or not) the person delivering the story (true or not true), and then judge the extent to which they thought they were told the truth. Interestingly, non-mimickers were more accurate in estimating the targets' truthfulness (Stel et al., 2009).

\section{Truthfulness Within Healthcare}

Truthfulness is particularly important in the context of healthcare. A good example of lying behaviors in this context is medication adherence. This is a key component of a successful health outcome (e.g., Ye et al., 2012) and yet non-adherence is a common practice in everyday life. It is estimated that at least half of all patients omit recommended doses of medicine (e.g., Cramer \& Rosenheck, 1998). It may be that physicians create a tendency in their patients to lie about their health, including intimate details, previous clinical interventions, or prescribed medications.

\section{The Goal of the Present Paper}

The literature shows that mimicry results in a liking for the person who is mimicked (Kulesza et al., 2015), and that mimickers are less accurate than non-mimickers in their estimations of truthfulness (Stel et al., 2009). We propose the hypothesis that participants who have been verbally and nonverbally mimicked will show a greater tendency to deceive the mimicker than participants who have not been mimicked.

Bell and DePaulo (1996) have shown that lying can enhance the well-being of people who are well-liked. Do people lie because of the well-being of the partner whom they protect from the harmful truth, or because they want to be liked? It is known that people who deliver negative, sad, harmful messages are perceived more negatively by others (Leary, 1995). Given that mimicry is a social glue, it is plausible that the mimicked participants have a greater desire for social acceptance. For instance, socially excluded participants used mimicry to be appreciated more (Lakin \& Chartrand, 2003). It is therefore possible that being mimicked makes people want to be appreciated, and lying may be a means to this end. Consequently, since mimicry creates liking toward the mimicker (Kulesza et al., 2015) we expect mimicry to be positively linked with lying since a lie may cause a deceptive person to be perceived favorably.

\section{Study 1}

\section{Method}

\section{Participants and Design}

Participants $(N=49)$ were students at a local university (32 women, 17 men: $M_{\text {age }}=28.7$ years, $S D_{\text {age }}=13.73$ ). They were randomly assigned to the experimental conditions and they received course credit for their participation.

The independent variable was verbal mimicry. In the experimental condition $(N=25)$, the confederate mimicked words spoken/expressed by the participant. In the control condition $(N=24)$, the confederate said: "yes" and "I understand" without mimicking the participant's words.

\section{Materials and Procedure}

The first dependent variable was the extent to which the participant liked the confederate. This was measured using a scale consisting of seven statements (e.g., "I like this person"), where the answer was measured using a 7-point Likert scale from $1=$ not at all to $7=$ fully agree. The average score for these seven statements created a "liking" score. The second dependent variable was a tendency to lie: 12 mathematical matrices (Mazar et al., 2008) with only one solvable exercise; the rest could not be solved. As a consequence, a score of more than 1 was an indicator of a tendency to lie. The study took place in a university laboratory. The experiment was conducted by a female psychology student who gave instructions. She was blind to the hypothesis but not to the experimental condition.

First, the confederate asked participants to read a text about mathematics as an essential field of science in everyone's life. The next step was a 10-minute interview about the role of mathematics in everyday life, during which the confederate verbally mimicked (or not) participants. In the mimicry condition, the confederate copied the statements, paraphrased, and adopted the participants' tone of voice. In the non-mimicry condition, the confederate summed up the statements with simple words like "okay." After the interview, participants completed a questionnaire to measure how much they liked the confederate.

Finally, participants were asked to solve 12 mathematical exercises (Mazar et al., 2008) in which they were asked to find the pairs of numbers adding up to "10" (e.g., 2.3 and 7.7 equals 10). At the end of this task, participants were asked to hide the sheet on which they were working and declare the number of solved exercises. Participants were unaware, however, that only one exercise was solvable, meaning anyone who claimed to have solved more than one was lying. Afterward the experimenter verbally asked participants whether they were aware that she was copying their statements or speech style. None of the participants reported any suspicions. All materials and data are publicly 
Table 1. Descriptive statistics for Study 1

\begin{tabular}{|c|c|c|c|c|c|c|c|c|c|c|}
\hline \multirow[b]{2}{*}{ Variables } & \multirow[b]{2}{*}{$\alpha$} & \multirow[b]{2}{*}{$\mathrm{Me}$} & \multirow[b]{2}{*}{ Mo } & \multirow[b]{2}{*}{ Skewness } & \multirow[b]{2}{*}{ Kurtosis } & \multirow[b]{2}{*}{ Min } & \multirow[b]{2}{*}{ Max } & \multicolumn{3}{|c|}{ Shapiro-Wilk } \\
\hline & & & & & & & & W & $d f$ & $p$ \\
\hline \multicolumn{11}{|l|}{ Verbal mimicry } \\
\hline Liking & .93 & 6.86 & 7.00 & -2.10 & 4.81 & 4.29 & 7.00 & .717 & 25 & $<.001$ \\
\hline Number of matrices solved & N/A & 2.00 & 3.00 & 0.67 & 0.09 & 0.00 & 7.00 & .936 & 25 & .122 \\
\hline \multicolumn{11}{|l|}{ No-mimicry } \\
\hline Liking & .76 & 5.36 & 5.14 & 0.61 & 0.39 & 4.43 & 7.00 & .959 & 24 & .422 \\
\hline Number of matrices solved & N/A & 1.00 & 1.00 & 2.24 & 5.05 & 0.00 & 7.00 & .646 & 24 & $<.001$ \\
\hline
\end{tabular}

Table 2. Independent student's t-test for verbal mimicry (Study 1)

\begin{tabular}{|c|c|c|c|c|c|c|c|c|c|c|c|c|c|}
\hline \multirow[b]{3}{*}{ Variables } & \multicolumn{4}{|c|}{ Group } & & & \multirow[b]{3}{*}{$t$} & \multirow[b]{3}{*}{$d f$} & \multirow[b]{3}{*}{$p$} & \multirow[b]{3}{*}{$d$} & \multirow[b]{3}{*}{$d_{\text {SESOI }}$} & \multirow[b]{3}{*}{$95 \% \mathrm{Cl}$} & \multirow{3}{*}{$\begin{array}{c}\text { Post hoc } \\
\text { test power } \\
1-\beta\end{array}$} \\
\hline & \multicolumn{2}{|c|}{$\begin{array}{l}\text { No-mimicry } \\
(N=24) \\
\end{array}$} & \multicolumn{2}{|c|}{$\begin{array}{c}\text { Verbal } \\
\text { mimicry } \\
(N=25) \\
\end{array}$} & \multicolumn{2}{|c|}{$\begin{array}{c}\text { Levene's } \\
\text { test }\end{array}$} & & & & & & & \\
\hline & $M$ & $S D$ & M & $S D$ & $F$ & $p$ & & & & & & & \\
\hline Liking & 5.48 & 0.59 & 6.55 & 0.13 & 0.10 & .966 & 5.94 & 47 & $<.001$ & 1.70 & .78 & {$[0.86,1.74]$} & .99 \\
\hline Number of matrices solved & 1.54 & 1.64 & 2.56 & 1.85 & 1.18 & .282 & 0.04 & 47 & .048 & 0.58 & .56 & {$[0.01,1.12]$} & .52 \\
\hline
\end{tabular}

accessible at the Open Science Framework (OSF; https:// osf.io/f9z3t/).

\section{Results}

Descriptive statistics are displayed in Table 1. Correlation analysis revealed a medium and positive linear correlation between liking and lying $(r=.301, p=.035)$.

A nominal variable was created based on the number of matrices solved. The first category included participants who declared possibly true answers (0 or 1$)$ and the second included participants who declared possibly false answers $(\geq 2)$. A $\chi^{2}$-test between experimental conditions and the nominal variable was significant, $\chi^{2}(1, N=49)=11.01$, $p=.001, \varphi=.47$. In the mimicry group, $68 \%$ of participants declared possibly false answers, and 32\% declared possibly true answers. In the control group, $20.8 \%$ of the participants declared possibly false answers, and $79.2 \%$ declared possibly true answers. This means that more people in the experimental group declared possibly false answers compared to the control group.

Furthermore, a one-sample $t$-test for the number of matrices solved showed that verbally mimicked participants $(M=2.56, S D=1.85)$ declared significantly more than one matrix to be solved, $t(24)=4.22, p<.001, d=.84,95 \% \mathrm{CI}$ $[0.80,2.32]$. In the control group $(M=1.54, S D=1.64)$, however, this result was not significant, $t(23)=1.62, p=$ $.120, d=.33,95 \%$ CI $[-0.15,1.23]$.

Finally, by independent $t$-test, we examined whether mimicry led to greater liking and a higher number of matrices solved. Power analysis was run ex post (see Table 2).
This study shows that respondents who were verbally mimicked lied to a greater extent. In Study 2, we tested whether this effect could be replicated using nonverbal mimicry, using a different group and another confederate.

\section{Study 2}

\section{Method}

\section{Participants and Design}

In total, 40 participants took part in the experiment: $\left(N=40,21\right.$ women, 19 men: $\left.M_{\text {age }}=43.3, S D_{\text {age }}=13.7\right)$. This time, we invited students from weekend courses. Most of these students were older people with full-time jobs. Participants were randomly assigned to experimental conditions and did not receive any payment or course credit.

The independent variable was nonverbal mimicry. In the mimicry condition $(N=20)$, the confederate mimicked the participants' body language. In the control condition $(N=20)$, mannerisms were not imitated.

\section{Materials and Procedure}

Dependent variables were the same as in Study 1: liking and tendency to lie. The male psychology student confederate was blind to the hypothesis and received only manipulation and randomization instructions. In the mimicry condition, behaviors were mimicked within $2 \mathrm{~s}$ of the participant completing them. Such behaviors included hand gestures (e.g., placing them on or removing them from the counter) and arm gesticulations and body stance such as leaning 
Table 3. Descriptive statistics for Study 2

\begin{tabular}{|c|c|c|c|c|c|c|c|c|c|c|}
\hline \multirow[b]{2}{*}{ Variables } & \multirow[b]{2}{*}{$\alpha$} & \multirow[b]{2}{*}{$\mathrm{Me}$} & \multirow[b]{2}{*}{ Mo } & \multirow[b]{2}{*}{ Skewness } & \multirow[b]{2}{*}{ Kurtosis } & \multirow[b]{2}{*}{ Min } & \multirow[b]{2}{*}{ Max } & \multicolumn{3}{|c|}{ Shapiro-Wilk } \\
\hline & & & & & & & & W & $d f$ & $p$ \\
\hline \multicolumn{11}{|l|}{ Nonverbal mimicry } \\
\hline Liking & .93 & 6.86 & 7.00 & -1.70 & 2.12 & 4.71 & 7.00 & .720 & 20 & $<.001$ \\
\hline Number of matrices solved & N/A & 2.50 & 1.00 & 0.53 & -0.71 & 0.00 & 8.00 & .927 & 20 & .133 \\
\hline \multicolumn{11}{|l|}{ No-mimicry } \\
\hline Liking & .89 & 5.50 & 5.57 & -0.18 & -0.24 & 4.00 & 7.00 & .970 & 20 & .749 \\
\hline Number of matrices solved & N/A & 0.50 & 0.00 & 0.63 & -1.11 & 0.00 & 7.00 & .762 & 20 & $<.001$ \\
\hline
\end{tabular}

Table 4. Independent Student's t-test for verbal mimicry (Study 2)

\begin{tabular}{|c|c|c|c|c|c|c|c|c|c|c|c|c|c|}
\hline \multirow[b]{3}{*}{ Variables } & \multicolumn{4}{|c|}{ Group } & & & \multirow[b]{3}{*}{$t$} & \multirow[b]{3}{*}{$d f$} & \multirow[b]{3}{*}{$p$} & \multirow[b]{3}{*}{$d$} & \multirow[b]{3}{*}{$d_{\text {SESOI }}$} & \multirow[b]{3}{*}{$95 \% \mathrm{Cl}$} & \multirow{3}{*}{$\begin{array}{c}\text { Post hoc } \\
\text { test power } \\
1-\beta\end{array}$} \\
\hline & \multicolumn{2}{|c|}{$\begin{array}{l}\text { No-mimicry } \\
(N=20) \\
\end{array}$} & \multicolumn{2}{|c|}{$\begin{array}{c}\text { Nonverbal } \\
\text { mimicry } \\
(N=20) \\
\end{array}$} & \multicolumn{2}{|c|}{$\begin{array}{c}\text { Levene's } \\
\text { test }\end{array}$} & & & & & & & \\
\hline & $M$ & $S D$ & M & $S D$ & $F$ & $p$ & & & & & & & \\
\hline Liking & 5.51 & 0.78 & 6.52 & 0.71 & 0.19 & .667 & 4.27 & 38.00 & $<.001$ & 1.35 & .66 & {$[0.35,1.49]$} & .98 \\
\hline Number of matrices solved & 0.70 & 0.80 & 3.20 & 2.40 & 22.08 & $<.001$ & 4.42 & 31.19 & $<.001$ & 1.40 & .64 & {$[1.33,3.67]$} & .99 \\
\hline
\end{tabular}

forward or sitting up straight. In the non-mimicry condition, the confederate sat still and straight with both hands in his lap and both feet on the ground. The rest of the procedure was identical to that in the previous study. After completing the procedure, the confederate verbally asked participants whether they had noticed that he was copying their movements and gestures. Again, none of the participants reported such suspicions. All materials and data are publicly accessible at the Open Science Framework (OSF; https:// osf.io/f9z3t/).

\section{Results}

Descriptive statistics are displayed in Table 3. The correlation analysis revealed a medium and positive linear correlation between liking and lie $(r=.462, p=.003)$.

As in the previous study a nominal variable was created based on the number of matrices solved. The first category included participants who declared possibly true answers (0 or 1 ) and the second included participants who declared false answers $(\geq 2)$. A $\chi^{2}$-test between experimental conditions and the nominal variable was significant, $\chi^{2}(1, N=40)$ $=10.1, p=.001, \varphi=.5$. In the mimicry group, $70 \%$ of participants declared possibly false answers, and 30\% declared possibly true answers. In the control group, $20 \%$ of the participants declared possibly false answers, and $80 \%$ declared possibly true answers. This means that more people in the experimental group declared possibly false answers compared to the control group.

Furthermore, one-sample $t$-tests for the number of solved matrices showed that the nonverbally mimicked participants $(M=3.2, S D=2.4)$ declared significantly more than one matrix to be solved, $t(19)=4.1, p=.001$, $d=.92,95 \%$ CI $[1.08,3.32]$, whereas the control group $(M=0.7, S D=0.8)$ did not, $t(19)=1.67, p=.110, d=.37$, 95\% CI [-0.68, 0.08].

As in the previous experiment, power analysis was run ex post. The results of the independent $t$-test (including test power) may be found in Table 4 .

\section{Discussion}

Two studies show that mimicry, both verbal and nonverbal, leads to a heightened tendency to lie to the mimicker. This is in line with previous findings that mimicry can have negative consequences, such as reduced self-esteem (Kot \& Kulesza, 2016). The findings also expand upon previous reports that mimickers are less accurate in detecting lies (Stel et al., 2009). Together these findings suggest that once one mimics, the chances of detecting a lie are significantly smaller, and the mimickee becomes more eager to lie.

There are still several unanswered questions. What are the mechanisms behind the phenomenon? Research shows that people tend to use less self-oriented lies to the ones they are close to (DePaulo et al., 1996). However, the literature also shows a positive link between lying and liking, yet only when the liar intends to benefit others (e.g., Cantarero et al., 2017). The relationship between liking and cheating found in this study might therefore be a case 
of spurious correlation stemming from the fact that mimicry tends to increase the liking of the mimicker.

It seems plausible that the mimicked participants lied to foster a more positive impression of themselves. Kot and Kulesza (2016) showed that being mimicked lowered participants' self-esteem and self-liking. Leander et al. (2011) showed that individuals performed worse when presented with a self-derogating stereotype when mimicked. It seems that the mechanism underlying the relationship between mimicry and dishonesty might be self-esteem, combined with building one's image in the mimicker's eyes. Previous studies have shown that inducing lower selfesteem leads to a higher propensity to cheat (Aronson \& Mettee, 1968). When individuals are presented with a task in which higher performance can serve as a self-esteem boost, they may be prone to over-report in order to restore their self-esteem. Loss of self-esteem resulting from the experience of being mimicked can lead people to take actions aimed at restoring self-esteem. Since effective self-presentation serves this purpose (Leary, 1995), people can cheat when cheating becomes a means of making a good impression on others.

We do not know what happens in an interaction where both kinds of mimicry take place. A $2 \times 2$ (Verbal $\times$ Nonverbal) experimental design should be used to answer this question. This could ascertain whether there is an additive effect between the two kinds of mimicry. The effect of mimicry could be binary (it either appears or it does not and the lying is constant), or it could be additive (more mimicry results in more lying).

A future study could assess whether lying increases or decreases as a function of the number of calculations that can be solved. For instance, would one expect the same results if six out of ten math problems were easy to solve? If not, what does this tell us about alternative explanations (e.g., self-presentation, shame) and underlying processes?

\section{Limitations}

One important caveat to our studies is the dependent measure as a proxy for lying. One may question whether this method measures the tendency to lie or something else, for example, a result of cognitive resource depletion or an honest mistake (for a critique, see e.g., Heyman et al., 2020). However, data across the two studies are consistent and replicate Mazar and colleagues' (2008) results. Future studies should introduce a different measure for lying.

The next limitation is the small sample size. One could argue that the result was obtained by chance. However, we found the same pattern of results in two studies, which elevates our trust that the heightened tendency to lie after having been mimicked was not found fallaciously.
It should also be mentioned that although the student confederates were blind to hypotheses, it cannot be ruled out that they could figure out the study's goal. Fortunately, the present studies were run by different confederates within different time periods, and in different locations. Moreover, the results are consistently relying on both verbal and nonverbal mimicry, which elevates our trust in the results. Most importantly, the vast majority of the literature shows that mimicry brings social benefits but not costs. If this literature was known to the confederate, they might have facilitated effects opposite to those uncovered here.

Another important issue is the generalizability of the results from students to clinical patients. One should keep in mind that clinical clients, due to many factors (such as age, depression, or any other psychological issue, and pharmacotherapy), may lie in a variety of ways. In the future, studies with clinical clients should be conducted.

Another important issue is the findings' practical implications. Should mimicry be removed from textbooks on psychotherapeutic techniques? In our opinion, the answer is no (or at least not yet). We still do not know the conditions under which participants lie more or who may be predisposed to this effect.

Practitioners should also remember that our experiments were conducted among strangers. This is an important point, since therapeutic sessions - besides the first one - take place among people who know each other well. Another issue is the time frame. Perhaps lying takes place only at the beginning of a relationship and not during frequent or prolonged interactions. After some time, lying may disappear when trust and deep understanding are formed. To address these issues, studies should be conducted during the therapeutic process.

To date, therapists are being taught the positive outcomes for therapeutic processes stemming from mimicry. The results presented here suggest that the picture is more nuanced. On the one hand, professional personnel using mimicry to administer psychological care gain a deeper insight into the client's problem, build greater liking and rapport, and increase the chance for therapeutic success. On the other hand, mimicry creates a greater risk of being lied to. It is a serious problem if we agree that the truth is crucial in the restorative process.

\section{References}

\footnotetext{
Aronson, E., \& Mettee, D. R. (1968). Dishonest behavior as a function of differential levels of induced self-esteem. Journal of Personality and Social Psychology, 9(2), 121-127. https://doi. org/10.1037/h0025853

Bell, K. L., \& DePaulo, B. M. (1996). Liking and lying. Basic and Applied Social Psychology, 18(3), 243-266. https://doi.org/ 10.1207/s15324834basp1803_1
} 
Cantarero, K., Parzuchowski, M., \& Dukala, K. (2017). White lies in hand: Are other-oriented lies modified by hand gestures? Possibly not. Frontiers in Psychology, 8, Article 814. https://doi. org/10.3389/fpsyg.2017.00814

Charny, J. E. (1966). Psychosomatic manifestations of rapport in psychotherapy. Psychosomatic Medicine, 28(4), 305-315. https://doi.org/10.1097/00006842-196607000-00002

Cramer, J. A., \& Rosenheck, R. (1998). Compliance with medication regimens for mental and physical disorders. Psychiatric Services, 49(2), 196-201. https://doi.org/10.1176/ps.49.2.196

Dabbs, J. M. Jr. (1969). Similarity of gestures and interpersonal influence. Proceedings of the Annual Convention of the American Psychological Association, 4(1), 337-338. https://psycnet. apa.org/record/1969-17366-001

DePaulo, B. M., Kashy, D. A., Kirkendol, S. E., Wyer, M. M., \& Epstein, J. A. (1996). Lying in everyday life. Journal of Personality and Social Psychology, 70(5), 979-995. https://doi.org/ 10.1037/0022-3514.70.5.979

Gallese, V., Keysers, C., \& Rizzolatti, G. (2004). A unifying view of the basis of social cognition. Trends in Cognitive Sciences, 8(9), 396-403. https://doi.org/10.1016/j.tics.2004.07.002

Guéguen, N. (2009). Mimicry and seduction: An evaluation in a courtship context. Social Influence, 4(4), 249-255. https://doi. org/10.1080/15534510802628173

Guéguen, N., Martin, A., Meineri, S., \& Simon, J. (2013). Using mimicry to elicit answers to intimate questions in survey research. Field Methods, 25(1), 47-57. https://doi.org/10.1177/ $1525822 \times 12449710$

Heyman, T., Vankrunkelsven, H., Voorspoels, W., White, A., Storms, G., \& Verheyen, S. (2020). When cheating is an honest mistake. Collabra: Psychology, 6(1), Article 12. https://doi.org/ 10.1525/collabra.294

Kot, S., \& Kulesza, W. (2016). The chameleon as a leech: The costs of mimicry for the mimickee. Polish Psychological Bulletin, 47(1), 131-135. https://doi.org/10.1515/ppb-2016-0014

Kulesza, W. M., Cisłak, A., Vallacher, R. R., Nowak, A., Czekiel, M., \& Bedynska, S. (2015). The face of the chameleon: The experience of facial mimicry for the mimicker and the mimickee. The Journal of Social Psychology, 155(6), 590-604. https:// doi.org/10.1080/00224545.2015.1032195

LaFrance, M., \& Broadbent, M. (1976). Group rapport: Posture sharing as a nonverbal indicator. Group and Organization Studies, 1(3), 328-333. https://doi.org/10.1177/105960117600100307

Lakin, J. L., \& Chartrand, T. L. (2003). Using nonconscious behavioral mimicry to create affiliation and rapport. Psychological Science, 14(4), 334-339. https://doi.org/10.1111/1467-9280.14481

Leander, N. P., Chartrand, T. L., \& Wood, W. (2011). Mind your mannerisms: Behavioral mimicry elicits stereotype conformity. Journal of Experimental Social Psychology, 47(1), 195-201. https://doi.org/10.1016/j.jesp.2010.09.002

Leary, M. R. (1995). Self-presentation: Impression management and interpersonal behavior. Westview.

Mazar, N., Amir, O., \& Ariely, D. (2008). The dishonesty of honest people: A theory of self-concept maintenance. Journal of Marketing Research, 45(6), 633-644. https://doi.org/10.1509/ jmkr.45.6.633

Meltzoff, A., \& Gopnik, A. (1993). The role of imitation in understanding persons and developing a theory of mind. In S. Baron-Cohen, H. Tager-Flusberg, \& D. J. Cohen (Eds.), Understanding other minds (pp. 335-366). Oxford University Press.

Paulick, J., Deisenhofer, A.-K., Ramseyer, F., Tschacher, W., Boyle, K., Rubel, J., \& Lutz, W. (2018). Nonverbal synchrony: A new approach to better understand psychotherapeutic processes and drop-out. Journal of Psychotherapy Integration, 28(3), 367-384. https://doi.org/10.1037/int0000099

Premack, D., \& Woodruff, G. (1978). Does the chimpanzee have a theory of mind? Behavioral and Brain Sciences, 1(4), 515-526. https://doi.org/10.1017/S0140525X00076512

Ramseyer, F., \& Tschacher, W. (2011). Nonverbal synchrony in psychotherapy: Coordinated body movement reflects relationship quality and outcome. Journal of Consulting and Clinical Psychology, 79(3), 284-295. https://doi.org/10.1037/a0023419

Stel, M., Van den Heuvel, C., \& Smeets, R. C. (2008). Facial feedback mechanisms in autistic spectrum disorders. Journal of Autism and Developmental Disorders, 38(7), 1250-1258. https://doi.org/10.1007/s10803-007-0505-y

Stel, M., Van Dijk, E., \& Olivier, E. (2009). You want to know the truth? Then don't mimic!. Psychological Science, 20(6), 693-699. https://doi.org/10.1111/j.1467-9280.2009.02350.x

Swaab, R. I., Maddux, W. W., \& Sinaceur, M. (2011). Early words that work: When and how virtual linguistic mimicry facilitates negotiation outcomes. Journal of Experimental Social Psychology, 47(3), 616-621. https://doi.org/10.1016/j.jesp. 2011.01.005

Van Baaren, R. B., Holland, R. W., Kawakami, K., \& Van Knippenberg, A. (2004). Mimicry and prosocial behavior. Psychological Science, 15(1), 71-74. https://doi.org/10.1111/ j.0963-7214.2004.01501012.x

Ye, S., Krupka, D. J., \& Davidson, K. W. (2012). Diagnosing medication non-adherence in a patient with myocardial infarction. Frontiers in Psychology, 3, Article 267. https://doi.org/ 10.3389/fpsyg.2012.00267

\section{History}

Received April 24, 2020

Revision received January 28, 2021

Accepted February 9, 2021

Published online September 9, 2021

\section{Open Data}

All materials and data are publicly accessible at the Open Science Framework (OSF; https://osf.io/f9z3t/).

\section{Funding}

NCN (Narodowe Centrum Nauki - Polish National Science Centre), Preludium Bis 1 grant, granted to Wojciech Kulesza (number: 2019/35/O/HS6/00420).

Financial support from Faculty of Psychology in Warsaw, SWPS University of Social Sciences and Humanities.

Open access of this article was financed by the Ministry of Science and Higher Education in Poland under the 2019-2022 program "Regional Initiative of Excellence", project number 012 / RID / 2018/19

\section{Pawet Muniak}

Center for Research on Social Relations

SWPS University of Social Sciences and Humanities

ul. Chodakowska 19/31

03-815 Warsaw

Poland

pmuniak@swps.edu.pl 